\title{
Article
}

\section{Influence of passive ultrasonic tip activation at different levels on the depth of sealer penetration: An in vitro study}

Ramlan, Nurul Ain, Abdullah, Dalia, Tiong, Timm Joyce, Spreafico, Diego and Kanagasingam, Shalini

Available at http://clok.uclan.ac.uk/33265/

Ramlan, Nurul Ain, Abdullah, Dalia, Tiong, Timm Joyce, Spreafico, Diego and Kanagasingam, Shalini (2020) Influence of passive ultrasonic tip activation at different levels on the depth of sealer penetration: An in vitro study. Saudi Endodontic Journal, 10 (2). pp. 116-120. ISSN 1658-5984

It is advisable to refer to the publisher's version if you intend to cite from the work. http://dx.doi.org/10.4103/sej.sej_109_19

For more information about UCLan's research in this area go to http://www.uclan.ac.uk/researchgroups/ and search for <name of research Group>.

For information about Research generally at UCLan please go to http://www.uclan.ac.uk/research/

All outputs in CLoK are protected by Intellectual Property Rights law, including Copyright law. Copyright, IPR and Moral Rights for the works on this site are retained by the individual authors and/or other copyright owners. Terms and conditions for use of this material are defined in the policies page. 


\title{
Influence of passive ultrasonic tip activation at different levels on the depth of sealer penetration: An in vitro study
}

\author{
Nurul Ain Ramlan, Dalia Abdullah', Timm Joyce Tiong², Diego Spreafico ${ }^{3}$, Shalini Kanagasingam ${ }^{4}$ \\ Department of Comprehensive Care Dentistry, Universiti Teknologi MARA, ${ }^{2}$ Department of Chemical and Environmental Engineering, \\ University of Nottingham Malaysia Campus, Selangor, ${ }^{1}$ Centre for Restorative Dentistry, Faculty of Dentistry, Universiti Kebangsaan \\ Malaysia, Kuala Lumpur, Malaysia, ${ }^{3}$ Private Practitioner, University of Milan, Italy, ${ }^{4}$ School of Dentistry, Faculty of Clinical and Biomedical \\ Sciences, University of Central Lancashire, Preston, United Kingdom
}

Abstract Introduction: The aim of this study was to compare the effect between different levels of ultrasonic tip activation on the depth of epoxy resin-based sealer (AH plus) dentinal tubules penetration.

Materials and Methods: Extracted single-rooted premolars $(n=60)$ were randomly allocated into three groups and instrumented following the same protocol. Group 1 (control), the sealer was mixed with $0.1 \%$ Rhodamine B dye and placed using size $20 \mathrm{~K}$-file. In Group 2, the sealer was passively activated using ultrasonic tip (ISO 25) $10 \mathrm{~s}$ mesiodistally and buccolingually at $2 \mathrm{~mm}$ from the apex. In Group 3, the sealer was activated in a similar manner at $4 \mathrm{~mm}$ from the apex. Samples were sectioned horizontally at $2 \mathrm{~mm}, 4 \mathrm{~mm}$, and $6 \mathrm{~mm}$ from the apex and analyzed using a stereomicroscope for tubular dentine sealer penetration. The cross-sectional area $\left(\mu \mathrm{m}^{2}\right)$ was measured with software to get the percentage of sealer penetration, and presences of voids were recorded. Results: Significant lesser percentage of sealer penetration into the dentinal tubules was observed between the control group and both the experimental groups $(P=0.00)$ at $2 \mathrm{~mm}, 4 \mathrm{~mm}$, and $6 \mathrm{~mm}$ from the apex. There was no significant difference in the percentage of sealer penetration into the dentinal tubules between both the experimental groups $(P>0.05)$. The presence of voids between all groups was not statistically significant $(P>0.05)$.

Conclusion: Passive ultrasonic activation of sealer placement resulted in deeper sealer penetration into the dentinal tubules even at a higher level of tip activation $(4 \mathrm{~mm})$.

Keywords: Depth of penetration, epoxy resin sealers, obturation, sonic, ultrasonic

Address for correspondence: Dr. Nurul Ain Ramlan, Faculty of Dentistry, Centre of Study Comprehensive Care, Universiti Teknologi MARA, Sungai Buloh Campus, Jalan Hospital, 47000 Sungai Buloh, Selangor, Malaysia.

E-mail: nurulain_ramlan@yahoo.com, ainramlan@uitm.edu.my

Submission: 17-07-19 Revision: 11-09-19 Acceptance: 14-09-19 Web Publication: ***

\section{INTRODUCTION}

Three-dimensional obturation is important to provide an impermeable, fluid-tight seal to prevent oral, and apical microleakage. ${ }^{[1]}$ One important component of the obturation is the placement of sealer. Conventional hand

\begin{tabular}{|l|l|}
\hline \multicolumn{2}{|c|}{ Access this article online } \\
\hline Quick Response Code: & Website: \\
\hline & www.saudiendodj.com \\
\cline { 2 - 2 } & \\
\hline
\end{tabular}

placement techniques of root canal sealers involve the use of reamers, absorbent paper points, lentulo spiral, and gutta-percha cones. ${ }^{[2]}$ The limitations of all the techniques are the inability of the sealer to penetrate into canal

This is an open access journal, and articles are distributed under the terms of the Creative Commons Attribution-NonCommercial-ShareAlike 4.0 License, which allows others to remix, tweak, and build upon the work non-commercially, as long as appropriate credit is given and the new creations are licensed under the identical terms.

For reprints contact: reprints@medknow.com

How to cite this article: Ramlan NA, Abdullah D, Tiong TJ, Spreafico D, Kanagasingam $\mathrm{S}$. Influence of passive ultrasonic tip activation at different levels on the depth of sealer penetration: An in vitro study. Saudi Endod $J$ 2020;XX:XX-XX. 
Ramlan, et al.: Influence of passive ultrasonic tip activation at different levels on the depth of sealer penetration: An in vitro study

irregularities and anatomical variations. Sealers may not be able to penetrate deep into dentinal tubules especially at the apical third of the root canal where most of the canal irregularities, i.e., accessory canal, apical delta, and anastomosis exist. ${ }^{[3]}$

The presence of voids and porosities in an unsatisfactory root canal filling and could lead to lower success rates compared to satisfactory root fillings. ${ }^{[4]}$ Bacteria are the main etiological factor for root canal failure, and it has been shown that they might be still present even after thorough chemomechanical preparation. ${ }^{[5,6]}$ Previous research has discovered that bacteria can penetrate up to $250 \mu \mathrm{m}$ into the dentinal tubules. ${ }^{[7]}$ The increased penetration of root canal sealer into dentinal tubules will further enhance the antimicrobial activity, thus decreasing the bacterial load within the root canal system. ${ }^{[8,9]}$ Furthermore, the mechanical interlocking of the sealer plug inside the tubules can further improve retention as well as the sealing ability of the sealer. ${ }^{[10]}$

Numerous techniques have been used to improve the distribution of root canal sealers within the root canal system. In vitro studies have shown that ultrasonically activated sealer placement showed a significantly higher percentage of depth of sealer penetration compared to other methods of sealer placement techniques. ${ }^{[1-13]}$ Due to the limitations of conventional sealer placement techniques, there is a need to improve the efficacy of sealer penetration into dentinal tubules, especially in the apical third of the root canal system. ${ }^{[14]}$ The aim of this study was to compare the depth of epoxy resin-based sealer (AH plus) penetration into the dentinal tubules with and without ultrasonic activation of the sealer. The effect of different levels of ultrasonic tip activation on the depth of sealer penetration into the dentinal tubules was investigated.

\section{MATERIALS AND METHODS}

Sixty freshly extracted human mandibular second premolar teeth extracted for orthodontic purposes were randomly divided into three groups. The sample size was calculated using sample size calculator (CTSI/UCSF-2013) and the sample size for each group was standardized to 20. Ethical approval was obtained from the Universiti Kebangsaan Malaysia (UKM) Ethics Committee (UKM 1.5.3.5/244/ DD/2015/002 (2)). Intact single-rooted mandibular second premolar teeth with complete root formation, sound, noncarious with no sign of resorption or previous root canal treatment were selected. Preoperative radiograph was taken and teeth with structural defects, caries, restorations, calcified canal, having open apices or apical foramen larger than $0.4 \mathrm{~mm}$, bifurcated canal, curvature more than $10^{\circ}$, having S-shaped or C-shaped canal were excluded from this study. Teeth were stored in 10\% formalin and kept within 1 month to avoid prolonged storage. Teeth were decoronated using diamond bur TC-11 (Mani, Japan) and the length of all teeth was standardized at $15 \mathrm{~mm}$. The working lengths were established by subtracting $0.5 \mathrm{~mm}$ from the point where a size $10 \mathrm{~K}$-file (Dentsply Maillefer, Ballaigues, Switzerland) penetrated the apical foramen. The teeth were then mounted in a silicone index and held by a jig during chemomechanical preparation. Canal cleaning and shaping were performed using Protaper Universal rotary files (Dentsply-Maillefer, Ballaigues, Switzerland). The canals were prepared using the S1 and S2 files, followed by the finishing files from size F1, size F2, size F3, and finally size F4. After the use of each instrument, the canals were irrigated with $2.5 \%$ sodium hypochlorite. Passive sonic irrigation was performed using EndoActivator with medium size tip (25/0.04) (Dentsply Tulsa Dental Specialties, California, USA) and a final rinse of $2 \mathrm{ml} \mathrm{17 \%}$ ethylenediaminetetraacetic acid (Meta Biomed, Co. Ltd., Chungbuk, Korea) was applied for $2 \mathrm{~min}$. Then, the canals were flushed with $2.5 \%$ of sodium hypochlorite followed by saline solution. Paper points size 40 (Dentsply Maillefer, Ballaigues, Switzerland) were used to dry the canals.

AH Plus sealer (De Trey, Dentsply, Konstanz, Germany) was mixed with Rhodamine B dye (Sigma-Aldrich, St. Louis, MO, USA) which is magenta-pink in color to achieve $0.1 \%$ concentration. ${ }^{[15]} \mathrm{A}$ size $20 \mathrm{k}$-file was used to place the sealer into all the canals, using a counterclockwise rotation. ${ }^{[16]}$ For the control group (Group 1), all canals were obturated right after sealer placement. The ultrasonic tip was placed at different levels for Group 2 and Group 3. For Group 2, the sealer was activated using a size $25 \mathrm{~K}$-file ultrasonic tip attached to the $120^{\circ}$ Endochuck (EMS, Switzerland) using an EMS MiniMaster motor (Piezon $\AA$, E. M. S. Electro Medical Systems S.A., Switzerland). A rubber stopper was placed, and the ultrasonic tip was inserted at $2 \mathrm{~mm}$ short from the working length. The ultrasonic file was activated using "endo" mode without water at 30\% low power setting. The file was activated for $10 \mathrm{~s}$ in a buccolingual direction and $10 \mathrm{~s}$ in a mesiodistal direction of the root canal. The same method of sealer placement was carried out in Group 3, except that the file was activated $4 \mathrm{~mm}$ short from the working length. After placement of sealers, all 60 canals were obturated using cold lateral condensation technique using prefitted size F4 ProTaper Universal (Dentsply-Maillefer, Ballaigues, Switzerland) gutta-percha points and accessory gutta-percha points. Gutta-percha was cut $3 \mathrm{~mm}$ from the orifice and condensed vertically with a heated plugger, and Cavit G (3M ESPE, 
Ramlan, et al.: Influence of passive ultrasonic tip activation at different levels on the depth of sealer penetration: An in vitro study

Germany) was placed as temporary filling. The teeth were stored in an incubator at $37^{\circ} \mathrm{C}$ and $100 \%$ humidity for 7 days, to allow the sealer to set. During sealer placement, freshly mixed sealer was used to obturate five canals per mixture. Sealer placement method was changed with every five teeth in each group and then shifted to another group to minimize operator becoming more proficient with one particular method and to avoid fatigue as a confounding variable. ${ }^{[17]}$

Each tooth was embedded in self-cured clear acrylic (Probase ${ }^{\circledR}-$ Brazil, Ivoclar Vivadent, Liechtenstein, Germany) and sectioned horizontally in a mesiodistal direction at $2 \mathrm{~m}, 4 \mathrm{~mm}$, and $6 \mathrm{~mm}$ from the apex using Isomet 4000 (Buhler®, Illinois, USA), which produces high polished slides. A high-resolution stereomicroscope (Zeiss Stemi 2000-C Stereo Microscope-7.7X to 1X Zoom Range, Jena, Germany) was used to observe each slice using 1.6X magnification and images of the slices were captured using AxioCam ERc5c-Zen Lite 2012 (Blue Edition) software. A single calibrated examiner measured the penetration of the pink-stain of Rhodamine B dye into the dentinal tubules of all the 180 slices. The correlation coefficient for intraexaminer reliability was 0.998 .

Surface areas of penetration were demarcated using the AxioCam ERc5c-Zen Lite 2012 software. Values of dentinal tubules penetration were recorded as "a," the surface areas of the inner perimeter of the canal walls were measured by demarcating the outline of the canals on the images as label "b," and the whole cross-sectional surface areas of the root (outer perimeter) were recorded in the same manner and labeled as "c" [Figure 1]. Then, the percentages of cross-sectional area $\left(\mu \mathrm{m}^{2}\right)$ of sealant penetration into dentinal tubules were calculated by similar method described by Aguirre et al. ${ }^{[17]}$ All images were

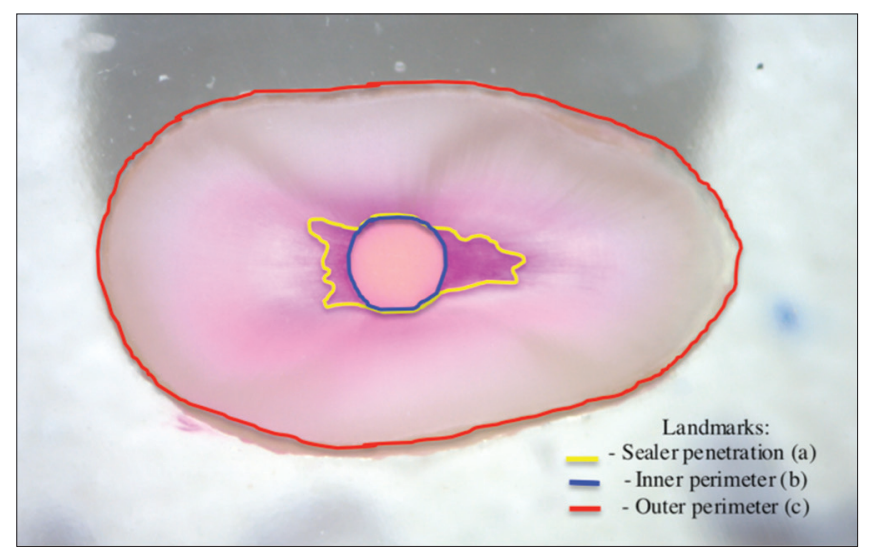

Figure 1: Image of the cross-sectional root surface showing the demarcation of the sealer penetration, inner perimeter of the canal wall and outer perimeter of the root surface also analyzed for the presence of voids at the interface between gutta-percha/sealer and the canal walls. Images were scored " 0 " if no voids were present and scored " 1 " if voids were present.

Statistical analysis was performed using Kruskal-Wallis test. Post hoc Mann-Whitney U-test was carried out to compare the differences between the control and Group 2 (ultrasonic activation at $2 \mathrm{~mm}$ ), Group 2 and Group 3 (ultrasonic activation at $4 \mathrm{~mm}$ ), and the control group and Group 3 at all levels tested. Fisher's exact test was carried out to compare the presence of voids between the control group, Group 2 and Group 3 at $2 \mathrm{~mm}, 4 \mathrm{~mm}$, and $6 \mathrm{~mm}$ from the apex.

\section{RESULTS}

Median and interquartile range for the percentages of depth of dentinal tubules sealer penetration for Group 1 , Group 2, and Group 3 at $2 \mathrm{~mm}, 4 \mathrm{~mm}$, and $6 \mathrm{~mm}$ were calculated. There were statistically significant differences of dentinal tubule penetration of sealers at all levels between the control group, Group 2, and Group 3 ( $H$ [corrected for ties $]=15.829[2 \mathrm{~mm}], 25.997[4 \mathrm{~mm}]$, and $27.74[6 \mathrm{~mm}]$, df $=2, n=60$, with $P=0.000$, and Cohen's effect size $[\nexists=0.942)$. Significant lower percentages of sealer penetration into the dentinal tubules were observed between the control group and both the experimental groups $(P=0.00)$ at $2 \mathrm{~mm}, 4 \mathrm{~mm}$, and $6 \mathrm{~mm}$ from the apex [Table 1]. There was no statistically significant difference in the percentage of sealer penetration into the dentinal tubules between both the experimental groups, which were Group 2 and Group $3(P>0.05)$. The presence of voids recorded between all the groups was not statistically significant at all levels $(P=0.863)$.

\section{DISCUSSION}

Ultrasonic method of sealer placement in this study resulted in significantly deeper penetration of sealer into the dentinal tubules compared to manual hand sealer placement which is similar to other studies. ${ }^{[15]}$ However, the difference is the manipulation of ultrasonic tip at several different levels which are at $2 \mathrm{~mm}$ and $4 \mathrm{~mm}$ that is not performed in the previous study. The results showed that the percentage of cross-sectional area $\left(\mu \mathrm{m}^{2}\right)$ for sealant penetration into dentinal tubules using ultrasonic was two to four times greater compared to the manual hand sealer placement when comparing the median value of control group (1.12) to the median value of Group 2 (2.73) and median value of Group 3 (4.16) at the level of $4 \mathrm{~mm}$ from the apex. Ultrasonic activation resulted in increased 
[Downloaded free from http://www.saudiendodj.com on Monday, May 11, 2020, IP: 46.208.192.123]

Ramlan, et al.: Influence of passive ultrasonic tip activation at different levels on the depth of sealer penetration: An in vitro study

Table 1: Result for the comparison of depths of sealer penetration using Mann-Whitney test

\begin{tabular}{lccc}
\hline & $\begin{array}{c}\text { Percentage of sealer penetration at } \\
2 \mathrm{~mm}(P)\end{array}$ & $\begin{array}{c}\text { Percentage of sealer penetration at } \\
4 \mathrm{~mm}(P)\end{array}$ & $\begin{array}{c}\text { Percentage of sealer penetration at } \\
6 \mathrm{~mm}(P)\end{array}$ \\
\hline Group 1 versus Group 2 & $0.000^{*}$ & $0.000^{*}$ & $0.000^{*}$ \\
Group 1 versus Group 3 & $0.000^{*}$ & $0.000^{*}$ & $0.000^{*}$ \\
Group 2 versus Group 3 & 0.678 & 0.289 & 0.142 \\
*There were statistically significant differences of dentinal tubules penetration of sealers at all levels between the control group, Group 2, and Group 3
\end{tabular}

penetration of sealer in this study may be attributed to the acoustic streaming field generated around an oscillating ultrasonic file as reported in previous studies. ${ }^{[18,19]}$ A study showed that higher velocity of streaming patterns was recorded using smaller size files (ISO 15, 20, and 25) compared to larger size files (ISO 30 and 35). ${ }^{[20]} \mathrm{A}$ size 25 stainless steel K-file attached to Endochuck $120^{\circ}$ (EMS, Switzerland) was used in this study to activate the sealer as it exhibited less displacement amplitudes compared to size 15 or $20 \mathrm{~K}$-file. This resulted in a decreased risk of binding with the canal wall, preventing damage to the root canal and may reduce the incidence of file separation. ${ }^{[21]}$ Currently, piezoelectrically powered devices have become the preferred choice compared to magnetostrictive devices as the former generates less heat. ${ }^{[22]}$ Furthermore, the use of piezoelectrically powered devices in this study was limited to $<15 \mathrm{~s}$, which was found in other studies to not generate sufficient heat that may cause injury to the periradicular tissue. ${ }^{[23]}$ Rhodamine $\mathrm{B}$ dye has been chosen as tracer dye to evaluate the sealer penetration in this study. Rhodamine $\mathrm{B}$ dye is a hydrophilic tracer dye used to determine the rate and flow direction of the sealer. Its molecular formula is $\mathrm{C}_{28} \mathrm{H}_{31} \mathrm{CIN}_{2} \mathrm{O}_{3}$ and its molecular weight is $536.1 \mathrm{~g} / \mathrm{mol}$ and particle size is $610 \mathrm{~nm} \cdot{ }^{[24]} \mathrm{It}$ is in the form of green crystals powder, which is very soluble in water. Rhodamine $B$ dyes fluoresce and take up a brilliant pink color on contact with water, thus could be detected easily or could be detected using fluorometers.

A recent study showed the use of the ultrasonic activation of an epoxy-amine resin-based sealer promoted greater sealer penetration even into the lateral canals. ${ }^{[25]}$ However, this is the first study, which has assessed the effect of different levels of tip activation on sealer penetration by adjusting the ultrasonic tip at two different levels $(2 \mathrm{~mm}$ and $4 \mathrm{~mm}$ ). This study showed that ultrasonic tip activation at $4 \mathrm{~mm}$ away from the apex resulted in similar depth of sealer penetration into the dentinal tubules compared to ultrasonic tip activation at $2 \mathrm{~mm}$ from the apex. As such, ultrasonic tip activation at $4 \mathrm{~mm}$ away from the apex may be an acceptable approach to achieve equally satisfactory penetration of sealer into the dentinal tubules. In natural teeth, the canal tends to curve either toward the labial or palatal aspect at about the apical third level. ${ }^{[2]}$ Therefore, in cases of severely curved canals, ultrasonic tip placed further away from the apex would also be better to minimize procedural errors, which would commonly occur beyond the canal curvature. The risk of iatrogenic injury in this study was also reduced with the use of file size 25, instead of smaller size files, which were reported to exhibit high incidence of file separation. ${ }^{\left[{ }^{[2]}\right.}$ The incidence of ultrasonic file separation ranges between $3.3 \%$ and $10 \% .{ }^{[27,28]}$ The file separations were located $2-3 \mathrm{~mm}$ away from the ultrasonic tip, and the probability of separating a file in apical third was $33 \%$, which is six times more likely when compared to coronal and middle thirds of the canal. ${ }^{[28]}$ Ultrasonic tip activation at this length $(4 \mathrm{~mm})$ may also reduce the incidence of iatrogenic damage, such as instrument separation, especially in curved canals.

There was no significant difference found in the presence of voids between ultrasonic methods of sealer placement compared to manual hand placement method of sealer placement. The limitations of this study include the use of stereomicroscope, which only allows two-dimensional image evaluation at a specific level of the root canal and artifact formation in some of the samples due to structural loss during cutting of the specimen. ${ }^{[29]}$ Nevertheless, the study does provide useful findings, as this is assessed the effect of different levels of tip activation on sealer penetration. For future studies, three-dimensional analysis using micro-computed tomography should be carried out to gain more in-depth view of sealer penetration.

In addition to that, patients' age and ethnicity were not taken into consideration in the sample selection, which may possibly lead to conflicting results on the presence of voids in comparison with other studies. It was found that increasing age might result in lesser penetration due to the increase in incidence of sclerosis. ${ }^{[30]}$ The rate of sclerosis also may differ between different ethnicity. ${ }^{[1]}$ As age and ethnicity may be associated with incidence and rate sclerosis, the results of this study may produce differing findings in terms of penetration of sealer. Therefore, for future studies, we would like to recommend inclusion of age and ethnicity of samples, as well as other factors that may impact on the condition of the dentinal tubules, and subsequent penetration of sealer. 


\section{CONCLUSION}

Passive ultrasonic activation of sealer placement resulted in a significantly higher percentage of sealer penetration depth into the dentinal tubules compared to manual hand sealer placement. Placement of the ultrasonic tip $4 \mathrm{~mm}$ from the apex during sealer placement is safer to prevent iatrogenic damage, without compromising the quality of sealer penetration.

\section{Financial support and sponsorship}

Nil.

\section{Conflicts of interest}

There are no conflicts of interest.

\section{REFERENCES}

1. Kumar A, Pai AR. Comparative assessment of the area of sealer voids in single cone obturation done with mineral trioxide aggregate, epoxy resin, and zinc-oxide eugenol based sealers. Saudi Endod J 2016;6:62-5.

2. Johnson JD. Root canal filling materials. In: Ingles JI, editor. Ingle's Endodontics. $6^{\text {th }}$ ed. Ontario: BC Decker Inc.; 2002. p. 1034-43.

3. Chandra SS, Shankar P, Indira R. Depth of penetration of four resin sealers into radicular dentinal tubules: A confocal microscopic study. J Endod 2012;38:1412-6.

4. Ng YL, Mann V, Gulabivala K. A prospective study of the factors affecting outcomes of nonsurgical root canal treatment: Part 1: Periapical health. Int Endod J 2011;44:583-609.

5. Möller AJ, Fabricius L, Dahlén G, Sundqvist G, Happonen RP. Apical periodontitis development and bacterial response to endodontic treatment. Experimental root canal infections in monkeys with selected bacterial strains. Eur J Oral Sci 2004;112:207-15.

6. Sundqvist G, Figdor D. Life as an endodontic pathogen. Endod Top 2003;6:3-28.

7. Siqueira JF Jr., Rôças IN, Favieri A, Lima KC. Chemomechanical reduction of the bacterial population in the root canal after instrumentation and irrigation with $1 \%, 2.5 \%$, and $5.25 \%$ sodium hypochlorite. J Endod 2000;26:331-4.

8. Bortolini MC, Ferreira dos Santos SS, Habitante SM, Rodrigues JR, Vance R, Jorge AO, et al. Endodontic sealers: Intratubular penetration and permeability to Enterococcus faecalis. Indian J Dent Res 2010;21:40-3.

9. Heling I, Chandler NP. The antimicrobial effect within dentinal tubules of four root canal sealers. J Endod 1996;22:257-9.

10. Zhang H, Shen Y, Ruse ND, Haapasalo M. Antibacterial activity of endodontic sealers by modified direct contact test against Enterococcus faecalis. J Endod 2009;35:1051-5.

11. Hoen MM, LaBounty GL, Keller DL. Ultrasonic endodontic sealer placement. J Endod 1988;14:169-74.

12. Stamos DE, Gutmann JL, Gettleman BH. In vivo evaluation of root canal sealer distribution. J Endod 1995;21:177-9.

13. Nikhil V, Bansal P, Sawani S. Effect of technique of sealer agitation on percentage and depth of MTA fillapex sealer penetration: A comparative in-vitro study. J Conserv Dent 2015;18:119-23.

14. Siqueira JF Jr., Rôças IN, Alves FR, Campos LC. Periradicular status related to the quality of coronal restorations and root canal fillings in a Brazilian population. Oral Surg Oral Med Oral Pathol Oral Radiol Endod 2005;100:369-74.

15. Guimarães BM, Amoroso-Silva PA, Alcalde MP, Marciano MA, de Andrade FB, Duarte MA, et al. Influence of ultrasonic activation of 4 root canal sealers on the filling quality. J Endod 2014;40:964-8.

16. Machado R, Silva Neto UX, Carneiro E, Fariniuk LF, Westphalen VP, Cunha RS, et al. Lack of correlation between tubular dentine cement penetration, adhesiveness and leakage in roots filled with gutta percha and an endodontic cement based on epoxy amine resin. J Appl Oral Sci 2014;22:22-8

17. Aguirre AM, el-Deeb ME, Aguirre R. The effect of ultrasonics on sealer distribution and sealing of root canals. J Endod 1997;23:759-64.

18. Ahmad M. Some observations on the mechanics of oscillation of ultrasonic files. Endod Dent Traumatol 1990;6:12-5.

19. Tiong TJ, Price GJ, Kanagasingam S. A computational simulation study on the acoustic pressure generated by a dental endosonic file: Effects of intensity, file shape and volume. Ultrason Sonochem 2014;21:1858-65.

20. Ahmad M, Pitt Ford TJ, Crum LA. Ultrasonic debridement of root canals: Acoustic streaming and its possible role. J Endod 1987;13:490-9.

21. Ahmad M. Measurements of temperature generated by ultrasonic file in vitro. Endod Dent Traumatol 1990;6:230-1.

22. Plotino G, Pameijer CH, Grande NM, Somma F. Ultrasonics in endodontics: A review of the literature. J Endod 2007;33:81-95.

23. Bailey GC, Cunnington SA, Ng YL, Gulabivala K, Setchell DJ. Ultrasonic condensation of gutta-percha: The effect of power setting and activation time on temperature rise at the root surface-an in vitro study. Int Endod J 2004;37:447-54.

24. Ozkantar N, Soylak M, Tuzen M. Spectrophotometric detection of rhodamine B in tap water, lipstick, rouge, and nail polish samples after supramolecular solvent microextraction. Turk J Chem 2017;41:987-94.

25. Arslan H, Abbas A, Karatas E. Influence of ultrasonic and sonic activation of epoxy-amine resin-based sealer on penetration of sealer into lateral canals. Clin Oral Investig 2016;20:2161-4.

26. Carrotte P. Endodontics: Part 4. Morphology of the root canal system. Br Dent J 2004;197:379-83.

27. Ahmad M. An analysis of breakage of ultrasonic files during root canal instrumentation. Endod Dent Traumatol 1989;5:78-82.

28. Iqbal MK, Kohli MR, Kim JS. A retrospective clinical study of incidence of root canal instrument separation in an endodontics graduate program: A PennEndo database study. J Endod 2006;32:1048-52.

29. Akman M, Akman S, Derinbay O, Belli S. Evaluation of gaps or voids occurring in roots filled with three different sealers. Eur J Dent 2010;4:101-9.

30. Paqué F, Luder HU, Sener B, Zehnder M. Tubular sclerosis rather than the smear layer impedes dye penetration into the dentine of endodontically instrumented root canals. Int Endod J 2006;39:18-25.

31. Whittaker DK, Bakri MM. Racial variations in the extent of tooth root translucency in ageing individuals. Arch Oral Biol 1996;41:15-9. 